\title{
Effect of Magnetic Treatment on Leaching Efficiency of Salts
}

\author{
Ashwini H. Gudigar* and Manjunatha Hebbara \\ Department of Soil Science and Agricultural Chemistry, University of Agricultural Sciences, \\ Dharwad, Karnataka-580005, India \\ *Corresponding author
}

A B S T R A C T

\section{Keywords}

Magnetic treatment,

Salinity levels, Magnetic

device, Leaching

efficiency, Leachate

Article Info

Accepted:

26 February 2018

Available Online:

10 March 2018
A column study was conducted to examine the effect of magnetic treatment on leaching efficiency of salts. Leaching a saline soil with magnetized water removed more salts from the soil compared to leaching with nonmagnetized water. Soils leached with magnetized water had significantly higher leachate salinity and lower soil salinity compared to leaching with non-magnetized water.

\section{Introduction}

Magnetized water is water passed through a magnetic field. Magnetic technology can become a useful tool, as proved by many researchers, to tackle problems related to reduced crop productivity due to use of saline water in agriculture. Magnetically treated water is reported to save on average, 20 per cent water with 10 per cent increased yields (Lin and Yotvat, 1990). This treatment would be beneficial in today's world with water scarcity and food shortages in many regions. Bogatin (1999) reported an increase in crop yield by $10-15$ per cent under magnetic water treatment due to (a) leaching of superfluous salts (b) better permeability of irrigated water and (c) better dissociation of mineral fertilizers. Increased permeability of water reduce the amount of water required for each irrigation event. Magnetized water has been used as an effective means for soil desalinization. Magnetized water applied to salty soil breaks down the salt crystals and helps in faster leaching of salts.

\section{Materials and Methods}

To investigate the effect of magnetized irrigation water on leaching efficiency of salts, column experiment was carried out. The PVC columns of $20 \mathrm{~cm}$ height and $7 \mathrm{~cm}$ diameter were used. The bottom was covered with end cap having $2 \mathrm{~mm}$ perforations to facilitate drainage. Saline soil having a salinity of 7.2 $\mathrm{dS} \mathrm{m}{ }^{-1}$ was used. Soil samples were collected 
from Shankarhatti, Athani Taluk, Belagavi district. The collected soil samples were air dried, ground to pass through $2.0 \mathrm{~mm}$ sieve and thoroughly mixed. Each PVC column was filled with $500 \mathrm{gm}$ of saline soil. The soil was filled in four parts. After filling each part (1/4), the column was tapped against a hard surface and the soil within the column was compacted with a suitable wooden hammer to ensure natural compaction of the soil, to the extent possible.

The soil columns filled with saline soil were leached with 1, 2, 3, 4 and 5 pore volumes of marginal saline water; both magnetically untreated and treated (three times passed). Separate sets of columns were maintained for passing 1, 2, 3, 4 and 5 pore volumes of water.

For example, in case of set one, one pore volume of water was passed through the columns (triplicate) and salinity of the leachate and salinity of the soil after leaching was estimated. In case of three pore volume treatment, first, one pore volume of water was passed, leachate was collected and analyzed for its salinity. Then second pore volume of water was passed and again leachate was collected and analyzed. Similarly, the process was repeated after passing third pore volume of water. After passing all the three pore volume of water, the soil samples were processed and analyzed for their salinity

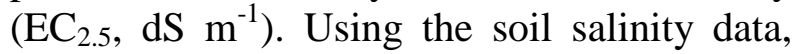
the leached fraction under different treatments including both magnetically untreated and treated were calculated.

\section{Results and Discussion}

To investigate the effect of magnetized irrigation water on leaching efficiency of salts, a column experiment was carried out. A saline soil having a salinity of $7.2 \mathrm{dS} \mathrm{m} \mathrm{m}^{-1}$ was leached with marginal saline water of $2.0 \mathrm{dS}$ $\mathrm{m}^{-1}$. Both soil salinity and salinity of leachate were estimated after leaching with predetermined volume/s of water. A saline soil $\left(7.2 \mathrm{dS} \mathrm{m}^{-1}\right)$ was leached with marginally saline water of $2 \mathrm{dS} \mathrm{m}$. The amount of leaching water used consisted of 1, 2, 3, 4 and 5 pore volumes.

Irrespective of magnetic treatment, incremental volumes of water passed progressively removed salts from the soil (Table 1). The first pore volume of water when applied did not amount to any leaching but was approximately enough to saturate the soil. Even then it contributed for a marginal increase in the soil salinity in soil applied with magnetized water. Further, when more and more pore volume of water was passed through the soil, the salinity values decreased. The decrease was from 7.20 to $1.15 \mathrm{dS} \mathrm{m}^{-1}$ under non-magnetized water treatment compared to a decrease from 7.3 to $1.08 \mathrm{dS}$ $\mathrm{m}^{-1}$ under magnetized water treatment. The per cent decrease in soil salinity was 84.0 and 85.2 for non-magnetized and magnetized water treatment, respectively. Under magnetized water treatment, faster removal of salinity was observed than in soils applied with non-magnetized water. For example, passing two pore volumes of non-magnetized water removed 50.7 per cent initial salts (initial salinity: $7.2 \mathrm{dS} \mathrm{m}^{-1}$ and after passing 2 pore volumes: $3.55 \mathrm{dS} \mathrm{m}^{-1}$ ) while the same of volume of water passing resulted in removal of 59.2 per cent of initial salts (initial salinity: $7.3 \mathrm{dS} \mathrm{m}^{-1}$ and after passing 2 pore volumes: $2.98 \mathrm{dS} \mathrm{m}^{-1}$ ) when magnetically treated. The electrical conductivity values of leachates leached with magnetized water were significantly higher compared to leaching with non-magnetized water as recorded after leaching with each pore volume (Table 2). The electrical conductivity values of leachates were higher during initial phase of leaching and decreased with progressive leaching with higher pore volume of water both under nonmagnetized and magnetized water leaching. 


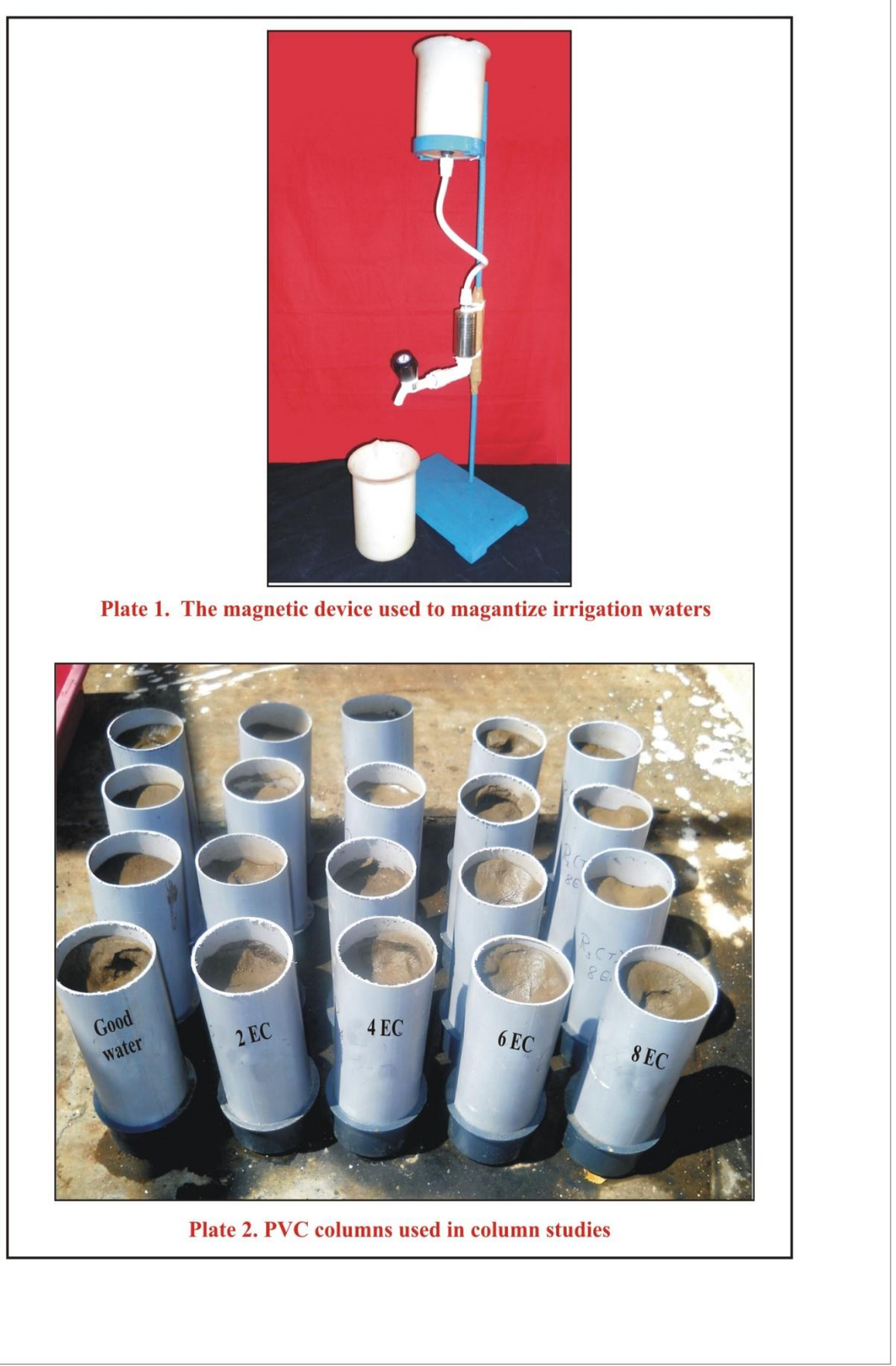


Table.1 Effect of leaching with magnetized water on soil salinity

\begin{tabular}{|l|c|c|}
\hline \multirow{2}{*}{ Pore volume } & \multicolumn{2}{|c|}{ EC $\left(\mathrm{dS} \mathrm{m}^{-1}\right)$} \\
\hline 1 & Magnetic untreated & Magnetic treated \\
\hline 2 & 7.20 & $\mathbf{7 . 3 0}$ \\
\hline 3 & 3.55 & $\mathbf{2 . 9 8}$ \\
\hline 4 & 2.53 & $\mathbf{1 . 9 0}$ \\
\hline 5 & 1.73 & $\mathbf{1 . 3 5}$ \\
\hline Mean & 1.15 & $\mathbf{1 . 0 8}$ \\
\hline & $\mathbf{3 . 1 5}$ & $\mathbf{2 . 7 8}$ \\
\hline SEm. \pm & Magnetic treatment $(\mathbf{M})$ & Pore volume \\
\hline CD $(\mathbf{P}=0.05)$ & $\mathbf{0 . 0 5}$ & $\mathbf{0 . 0 5}$ \\
\hline
\end{tabular}

Table.2 Effect of leaching with magnetized water on electrical conductivity (EC) of leachate

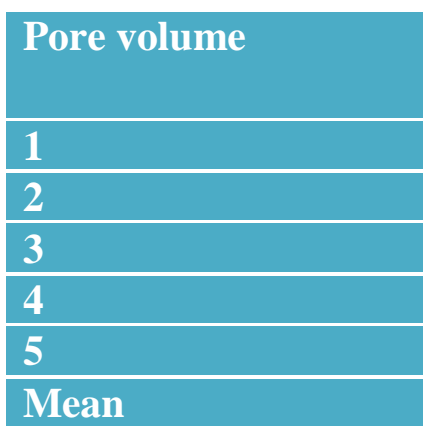

\begin{tabular}{|c|c|}
\hline \multicolumn{2}{|c|}{$\mathrm{EC}\left(\mathrm{dS} \mathrm{m}^{-1}\right)$} \\
\hline Magnetic untreated & Magnetic treated \\
\hline 0.00 & $\mathbf{0 . 0 0}$ \\
\hline 30.75 & $\mathbf{3 7 . 0 0}$ \\
\hline 24.25 & $\mathbf{2 7 . 2 5}$ \\
\hline 19.30 & $\mathbf{2 2 . 5 0}$ \\
\hline 15.85 & $\mathbf{1 8 . 3 5}$ \\
\hline $\mathbf{2 2 . 5 4}$ & $\mathbf{2 6 . 2 8}$ \\
\hline
\end{tabular}

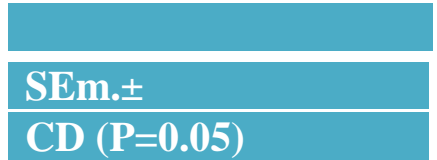

Magnetic treatment (M)

\begin{tabular}{|c|c|c|}
\hline 0.36 & 0.36 \\
\hline 1.11 & 1.11 \\
\hline
\end{tabular}

After leaching with each pore volume of water, leachate of magnetized water treatment contained higher salinity than under nonmagnetized water leaching. After passing five pore volumes of water, the mean salinity of leachate leached with non-magnetized water was $15.85 \mathrm{dS} \mathrm{m}^{-1}$ while, for magnetized water leaching, it was $18.35 \mathrm{dS} \mathrm{m}^{-1}$.

The magnetized water significantly influenced the salinity of the leached soil. Soils leached with magnetized water showed significantly lower salinity values, irrespective of volume of water passed over magnetic untreated water leaching. This was obviously due to removal of more salts by magnetized water than non- magnetized water. Across volume of water applied, soil columns leached with magnetized $2 \mathrm{EC}$ water had a significantly lower salinity of $2.78 \mathrm{dS}$ $\mathrm{m}^{-1}$ compared to leaching with nonmagnetized water $\left(3.15 \mathrm{dS} \mathrm{m}^{-1}\right)$.

It was found that salt removal decreased with progressive leaching. Alleman (1985) showed that desalination of a saline soil was 29 per cent greater in the first leaching and 33 per cent greater in the second leaching with magnetized water compared to untreated water. 
Electrical conductivity of leachates was significantly influenced by magnetic water treatment. The magnetic treatment caused a significant increase in the salinity of leachates compared to non-magnetized water indicating more removal of salts from the saline soil.

It was found that salt removal decreased with subsequent leaching frequency or with increased pore volumes. Total soluble salts concentration in the first leachate of all columns was higher compared with subsequent leachates while it was lower in the last leachate. Similar results were reported in literature.

Mohammed and Baseem (2013) showed that electrical conductivity values $\left(\mathrm{EC}, \mathrm{dSm}^{-1}\right)$ in water leachates of columns irrigated with magnetized water were higher compared with non-magnetized water. He concluded that magnetizing the irrigation water plays an important role in removing the soluble salts from the soil. Hilal et al., (2002) reported that magnetized water not only increased the leaching of excess soluble salts but also dissolved slightly soluble salts such as carbonates, phosphates and sulfates in soil.

Leaching a saline soil with magnetized water removed more salts from the soil compared to leaching with non-magnetized water. Soils leached with magnetized water had significantly higher leachate salinity and lower soil salinity compared to leaching with non-magnetized water.

\section{References}

Alleman, J. E., 1985. A performance evaluation for magnetic water treatment. Fourth Domestic Water Quality Symposium, ASAE and Water Quality Association Research Reports.

Bogatin, J., Bondarenko, N., Gak, E., Rokhinson, E. and Ananyev, I., 1999, Magnetic treatment of irrigation water: Experimental results and application conditions. Environ. Sci. Tech., 33(8): 1280-1285.

Hilal, M. H., Shata S. M., Abdel-Dayem A. A. and Hillal, M. M., 2002, Application of magnetic technologies in desert agriculture. III - Effect of magnetized water on yield and uptake of certain elements by citrus in relation to nutrients mobilization in soil. Egypt $J$. Soil.Sci., 42(1): 43-55.

Lin, I.and Yotvat, J., 1990, Exposure of irrigation and drinking water to a magnetic field with controlled power and direction. J. Magnetism and Magnetic Materials, 83: 525-526.

Mohamed and Bassem, M. E., 2013, Effect of magnetic treated irrigation water on salt removal from a sandy soil and on the availability of certain nutrients. Int. $J$. Engg. Appl. Sci., 2(2): 36- 44.

\section{How to cite this article:}

Ashwini H. Gudigar and Manjunatha Hebbara. 2018. Effect of Magnetic Treatment on Leaching Efficiency of Salts. Int.J.Curr.Microbiol.App.Sci. 7(03): 3363-3367. doi: https://doi.org/10.20546/ijcmas.2018.703.388 